\title{
Representaciones del devenir de la persona entre los ashaninka del Oriente peruano
}

\section{Enrique Carlos Rojas Zolezzi}

\section{(2) OpenEdition \\ Journals}

Edición electrónica

URL: https://journals.openedition.org/jsa/3206

DOI: $10.4000 /$ jsa. 3206

ISSN: 1957-7842

Editor

Société des américanistes

\section{Edición impresa}

Fecha de publicación: 1 junio 2006

Paginación: 255-278

ISSN: 0037-9174

\section{Referencia electrónica}

Enrique Carlos Rojas Zolezzi, «Representaciones del devenir de la persona entre los ashaninka del Oriente peruano», Journal de la Société des américanistes [En línea], 92-1 et 2 | 2006, Publicado el 15 enero 2012, consultado el 02 septiembre 2022. URL: http://journals.openedition.org/jsa/3206 ; DOI: https://doi.org/10.4000/jsa.3206 


\title{
NOTES DE RECHERCHE
}

\section{REPRESENTACIONES DEL DEVENIR DE LA PERSONA ENTRE LOS ASHANINKA DEL ORIENTE PERUANO}

\author{
Enrique Carlos ROJAS ZOLEZZI *
}

\section{INTRODUCCIÓN}

El presente informe aborda el tema de las representaciones sobre la persona en la sociedad ashaninka (arawak preandina) de la Amazonía peruana ${ }^{1}$. La universal conciencia de sí mismo frente a los otros ha sido objeto de estudio comparativo en la antropología desde las investigaciones pioneras de Mauss hasta la actualidad. En la cuenca amazónica el problema de la definición de la persona fue abordado inicialmente en los años 1970 (Da Matta, Seeger y Viveiros de Castro 1979; Viveiros de Castro 1979; Crocker 1983; Viertler 1979; HughJones 1979) tomando como estrategia de acercamiento el estudio de la producción social del cuerpo, perspectiva que ha continuado siendo seguida hasta los años recientes (Alès 1998; Taylor 1996, 1998; Vilaça 2002). Dichos estudios compartían en mayor o menor medida la perspectiva de que es en la confrontación con la sociedad que se inscribe en el cuerpo el orden social y que es en este proceso que la persona humana es definida. Posteriormente, las informaciones etnográficas producidas en la cuenca amazónica en el campo de los estudios de ecología simbólica (Descola 2005; Viveiros de Castro 1998) mostraron el carácter relacional de las cosmologías de esta región del mundo y que en éstas las concepciones sobre la persona no pueden ser entendidas sino en las relaciones contrastivas que los humanos sostienen con las otras categorías de seres que constituyen su entorno, objetos inanimados, plantas, animales y espíritus (Descola $i b i d$.). Como veremos en el sistema de representaciones ashaninka, el carácter de persona no está predefinido, estático y estable, sino que constituye una

* Docteur en anthropologie sociale et ethnologie, ciudad de San Sebástian, Guipuzcoa, Espagne [ecrz63@hotmail.com].

Journal de la Société des Américanistes, 2006, 92-1 et 2, pp. 255-278. O Société des Américanistes. 
cualidad que depende del grado de adecuación a modelos socialmente definidos de las relaciones sociales sostenidas con los seres humanos y no humanos del entorno.

\section{LOS HUMANOS ASHANINKA Y LO VIVIENTE}

En la categorización ashaninka de lo viviente se parte de una oposición básica entre lo viviente inmóvil y lo viviente móvil. Lo viviente inmóvil son las plantas; lo viviente móvil son los humanos y no humanos que tienen capacidad de desplazamiento. Los vivientes móviles son clasificados según el tipo de desplazamiento que les caracteriza (anitáchiri, caminando a cuatro patas; kamatsatáchiri, arrastrando el vientre; amatsekáchiri, dando saltos en el suelo; mitaháchiri, dando saltos de rama en rama de los arbustos y árboles; timahatirori, a través del agua; wankitáchari, volando) (Rojas Zolezzi 2003). En todos los casos, lo viviente, móvil o inmóvil, es clasificado a partir de un principio de categorización de tipo prototípico (Berlin 1992). Éste constituye un modo de clasificación según el cual a partir de la similitud de características morfológicas son reunidas diferentes especies similares alrededor de una considerada la más perfecta. Así, por ejemplo en el caso ashaninka tenemos entre las plantas cultivadas el caso del " verdadero maíz », shinkiperori (shinki, maíz; -pero, veritativo; -ri, tercera persona masculina), alrededor del cual son clasificadas las variedades « folk » de este cultígeno (Rojas Zolezzi 1997). En el caso de los animales se sigue también este modelo de clasificación. Kitaka Mendes (citado por Lenaerts 2002, pp. 99100) ha encontrado entre los ashaninka del Juruá brasileño términos como meyri pero (ardilla verdadera) y onkiro pero (rata verdadera), términos que avalan esta interpretación. Para algunas categorías de animales, existen términos genéricos, pero en el sistema de clasificación ashaninka esa forma de clasificación se presenta de forma muy restringida. Este es el caso de maranke, término que designa el conjunto de las serpientes, aunque al interior de esta categoría se definen grupos en torno a especies consideradas prototípicas. Estos principios de clasificación son utilizados en las representaciones ashaninka de las relaciones de los humanos con los seres de la naturaleza.

En la lengua ashaninka, atsiri es un término genérico que designa el ámbito de los humanos, sean ashaninka o pertenecientes a otros grupos. Siguiendo el principio de la clasificación prototípica, la humanidad se define por referencia a la forma (inásheta) antropomorfa en términos de cercanía o lejanía de una figura prototípica que en este caso es el sol Oriatsiri (oria, brillar; atsiri, humano). A este ser le es atribuida una forma antropomorfa, aunque resplandeciente, y es considerado el humano más perfecto. Dentro del mito cosmogónico el conjunto de los seres vivientes, es decir otros grupos humanos, plantas y animales, son ubicados en una jerarquía de acuerdo al grado de proximidad o lejanía en 
relación a dicho prototípico Oriatsiri. Oriatsiri, prototipo de humanidad, es asimismo el donador de las reglas que permiten la construcción de la sociedad como sistema. En la mitología ashaninka, es el sol quien establece la regla de incesto: este castiga a su esposa por haber tenido relaciones sexuales con uno de sus hijos. El hecho es descubierto cuando el sol encuentra que este último tenía adheridas al pene las hojas de la planta de coca (Eritroxilon sp.) que salían del sexo de esta mujer y de las que hasta entonces sólo el se servía. Ambos son castigados con la pérdida de su forma humana. La mujer es transformada en el arbusto de la coca y el hijo es quemado y transformado en un ave de plumaje negro tsiyá (no identificado) (Varese 1970, pp. 166-167; Anderson 1985, III, pp. 138-141; Lenaerts 2002, pp. 405-406). Asimismo el sol prohibe el canibalismo, abominado por los ashaninka, cuando transforma en el pez shimá (Prochilodus sp.), prototipo del conjunto de todos los peces, a un hombre que mascaba carne humana como si fuera una corteza que los ashaninka acostumbran consumir junto con la coca (Weiss 1975, p. 304). De este modo, el sol define en el tiempo primordial las reglas a partir de las cuales es construida la sociedad de los humanos.

De acuerdo al mito cosmogónico, alrededor de la figura prototípica de Oriatsiri son ubicados los demás seres antropomorfos. Oriatsiri es considerado un ashaninka, hijo de una mujer ashaninka, principio femenino que da a luz al sol en el tiempo primordial. Ésta es fertilizada por el principio masculino fecundador por excelencia, la luna, llamado en ashaninka Kashiri (kashi, esperma; -ri, tercera persona masculina), nombre que puede ser traducido como « el fecundador », ser que aún hoy, desde la lejanía en el cielo, estimula la reproducción y el crecimiento de las plantas, de los animales del bosque y de los cultígenos de los huertos. La relación de parentesco de los ashaninka con el principio femenino define en este sistema la ubicación de este grupo en un lugar central dentro de esta categoría en la cercanía máxima al sol prototípico Oriatsiri. En este sistema, los ashaninka han existido siempre. Sin embargo, sucesivas inundaciones de la tierra han producido la muerte y desaparición de poblaciones ashaninka anteriores, las que se han regenerado nuevamente a partir de la familia de un chamán sobreviviente. Estos cataclismos se producen ante la generalización de la guerra y la proliferación de seres malevolentes (kamari) sobre esta tierra, momento en que un gran cangrejo que habita al final del río que atraviesa el territorio ashaninka bloquea la salida del agua hacia los niveles inferiores del cosmos. El resto de los seres vivientes, es decir los otros grupos humanos, plantas y animales, son ubicados en una jerarquía de acuerdo al grado de proximidad o lejanía en relación a dicho prototípico Oriatsiri y a los ashaninka, los humanos por excelencia. En el citado mito cosmogónico ashaninka en sus diferentes versiones (Kindberg 1959; Weiss 1975, pp. 375-389; Varese 1970; Fernández 1986, pp. 176178; Butner 1989, p. 11; Rojas Zolezzi 2004, pp. 183-185), el resto de los seres vivientes tienen también origen en el señalado principio femenino. A lo 
largo del proceso de parto que da nacimiento al sol, el principio femenino, esta mujer ashaninka primordial, da origen a los otros grupos humanos (blancos, negros y quechuas de las altas tierras) en la forma de un primer sol que es despedazado por la luna. Estos ocupan un lugar hacia la periferia de la categoría de atsiri. Asimismo, a lo largo de dicho proceso de parto, el principio femenino da origen, a través de esputos sucesivos, a los diferentes animales agrupados en dos grandes categorías, aquellos que constituyen presas comestibles (poshini) y aquellos que producen enfermedades si son comidos en etapas críticas de desarrollo o de ocasionales debilitamientos del cuerpo llamados también « los que rompen huesos » (ikaharantayete). En este mito, el principio femenino da también origen a un árbol (maarmotiki) el que sostiene a la tierra kipatsi sobre la que todos estos seres viven. Otros mitos complementan el cuadro al explicar la definición de las diferencias entre humanos y animales. Así, es el demiurgo Awíreri, divinidad que se desdobla en un personaje que le acompaña, su nieto Kiri, quien define la humanidad o la no humanidad de los seres vivientes que se desplazan a través de la transformación de su fisicalidad, es decir la piel y las características morfológicas de los cuerpos de éstos, los que en el tiempo primordial tenían forma humana. Mientras que el demiurgo Awíreri y su nieto Kiri definen a los demás seres vivientes móviles como distintos en su fisicalidad a los humanos, otra divinidad que es considerada su hermana, la sal Tsiwi, que también presenta características demiúrgicas, define el intercambio de bienes como la forma de relación propia a la humanidad ashaninka al instituir el comercio de monedas de sal, al transformarse a sí misma en sal gema (Rojas Zolezzi 1994, pp. 49-51; 2004, pp. 243-247). De esta forma, a partir de un estado inicial de indiferenciación de los seres vivientes en que todos tienen forma humana, es establecida toda una jerarquía de los seres vivientes en que unos se constituyen en divinidades y otros son transformados en animales. Asimismo, la jerarquía entre grupos étnicos es remarcada en una explicación alternativa del origen de estos: la destrucción por el fuego de un ave rapaz caníbal que devoraba sistemáticamente a los ashaninka que se desplazaban por el río en balsas, da origen, por la transformación de sus restos carbonizados, en los blancos y negros (Rojas Zolezzi 2004, pp. 302-305) y por la transformación de sus plumas en los yine piro (Fernández 1984). De este modo, por el recurso a la atribución de un origen caníbal, práctica abominada en este sistema, es establecida una jerarquía entre grupos humanos. Los mitos citados en su conjunto establecen diferencias y jerarquías entre los seres vivientes donde inicialmente existía una relación de igualdad e indistinción tomando como referencia al sol, el humano brillante, como prototipo.

Cabe subrayar aquí que en este sistema en último término todos los animales y las plantas cultivadas son seres que perdieron su forma originalmente humana en el tiempo primordial. A los cultígenos se les atribuye ser el resultado de la transformación de los miembros de la familia del chamán sobreviviente del 
último cataclismo cósmico que destruyera una humanidad anterior, acto que ha permitido que éstos existan hasta hoy en los huertos (Rojas Zolezzi 1997). En el caso de los animales, se les atribuye ser ashaninkas transformados, sea por la divinidad solar o por el demiurgo Awíreri, quienes les impusieron sus características morfológicas actuales. Constituyen en este sentido los seres que son ubicados en la lejanía extrema del prototipo solar. Sin embargo, la frontera entre lo humano y lo no humano no está claramente trazada y queda ambigua. Esto se muestra con claridad en el caso de algunos no humanos, plantas cultivadas y ciertos mamíferos los que en ciertos contextos pueden ser llamados atsiri como en el caso de la yuca kaniri (manihot). Asimismo, a pesar de su fisicalidad distinta evidente, se atribuye a los animales una forma de vida y modos de conducta análogos a los de los humanos: la ardilla roja meiri es la dueña del fuego de cocina y de aquel utilizado en quemar los lugares rozados; la falcónida shimakowari es considerada el más experto pescador; la rapaz amémpori (Vultur gryphus) es considerada el más hábil cazador y guerrero (Rojas Zolezzi 1994, pp. 165, 204) y se dice que cuando las ranas y sapos cantan es que están teniendo una gran reunión de bebida como las realizadas por los humanos (Weiss 1975, p. 356). De este modo, según este sistema de representaciones los no humanos interactúan entre sí y se comunican con intenciones, sentimientos y medios semejantes a las de los humanos. Si la fisicalidad distinta a la de los seres humanos se atribuye a transformaciones ocurridas en el tiempo primordial, en este sistema de representaciones, les es atribuida a los no humanos también una interioridad semejante a la de aquellos, suerte de personas envueltas en una piel distinta a ojos de los humanos.

A pesar de estas similitudes atribuidas a humanos y no humanos, se subraya la relación de jerarquía ya señalada que unos y otros sostienen dentro del cosmos. Ésta no se define únicamente en referencia a la forma (inásheta) antropomorfa ya que el componente físico de la persona guarda correspondencia con la interioridad de esta última por múltiples y recíprocas determinaciones. Así pues, está relacionada con el desarrollo de la interioridad de los seres, lo que depende también del carácter de las relaciones que uno establezca con los otros seres, humanos y no humanos a lo largo de su vida. Como veremos, la construcción social de cada humano en este sistema es un proceso progresivo que implica la construcción de relaciones con adecuación a las reglas de la sociedad y de ello depende que durante su vida mantenga su calidad de humano y, tras la muerte, su lugar entre los seres en el cosmos.

\section{LAS PARTES de La PERSONA HUMANa}

En la concepción ashaninka, los humanos están formados de varios componentes: el owatsa, el tasonkantsi y el ishire siendo el desarrollo de este último en los 
humanos el que define la posición de éstos por encima de los no humanos en la jerarquía de los seres en el cosmos. El término owatsa hace referencia a la carne, y aunque los huesos otonki son parte del cuerpo, se utiliza el primer término para referirse al conjunto del cuerpo del individuo, es decir a la exterioridad de la persona. De este modo, el feto es llamado iwámento ( $i$-, tercera persona singular masculina; owatsa, carne; mento, nominalizador) literalmente, " objeto de carne ». A este se sumarán posteriormente los otros componentes. Los ashaninka reconocen el rol jugado en el engendramiento tanto por el hombre como por la mujer y consideran que el esperma masculino y la sangre femenina están en el origen de la concepción del individuo. Carne y huesos son indistintamente resultados de la participación del padre y la madre. El cuerpo es considerado consubstancial a las plantas y a los animales, lo que tiene una expresión lingüística en una serie de términos con los cuales son designadas partes tanto de unos $y$ otros ${ }^{2}$.

El elemento tasonkantsi, "el soplo», es el elemento que anima a los seres vivos, el que es recibido de las divinidades tasorentsi, término cuya traducción literal es «los que soplan». La lengua ashaninka no presenta una palabra equivalente al término " vida » y para decir que una persona está viva y que no ha fallecido, dicen que ella respira (nanei, " yo respiro »). El término itasonkapákeri quiere decir el soplo de las divinidades que hace vivir a los seres.

El otro principio constitutivo de todo humano es el ishire, el que tiene su asiento en el corazón, asánkane, el que en ciertos contextos puede ser llamado noshire (no, la persona; shire, alma) como ya había encontrado Weiss (1975, pp. 426-427). Este elemento se encuentra ligado a su capacidad de pensar o razonar (kenkeshirentsi). Su desarrollo, como veremos, depende de la obtención de conocimientos (yotaantsi). Los ashaninka, como ha señalado Weiss (ibid.), llaman también al corazón de un animal irasankana e ishire, lo que guarda coherencia con el hecho de que se atribuye a los animales cierto nivel de sensibilidad, razonamiento y capacidad de comunicación. Sin embargo, es sólo atributo de los humanos atsiri desarrollarlo mediante la adquisición de conocimientos yotaantsi (destrezas y aptitudes adquiridas, obtención de la lengua, el aprendizaje del comportamiento social y las reglas de la sociedad), lo que en esta concepción lo acercará al modelo prototípico de humano y definirá el lugar del individuo en la sociedad y el cosmos. El término ishire, traducido por los misioneros siguiendo la concepción neo-platónica de alma como algo opuesto e independiente del cuerpo es pues, para los ashaninka, algo muy distinto. En las concepciones de este grupo, el ishire no procede de ningún área trascendente del cosmos y como ya pudo entender Elick (1969) en la concepción ashaninka, el ishire es un principio que se va desarrollando en el individuo a medida que éste va adquiriendo las formas de conducta sociales y el conocimiento acerca de la estructura y funcionamiento del mundo ${ }^{3}$. 
Tanto el tasonkantsi como el ishire son elementos que constituyen la interioridad de cada humano. Las relaciones que sostienen con el owatsa o fisicalidad de cada individuo son complejas como veremos.

En la lengua ashaninka ser engendrado y nacer son hechos designados por el término timatsi, el que puede ser traducido como " existir». Como hemos señalado en el proceso de traer a existencia a un niño son reconocidos los roles jugados tanto por el padre como por la madre como genitores. Así es posible decir en lengua ashaninka iri timakeriri jorge, " a el lo engendró Jorge », " a el lo trajo a existencia Jorge ». De la misma manera es posible decir timake otsomonte « ella ha concebido y tiene el vientre hinchado » o más precisamente « ella ha traído a existencia y tiene el vientre hinchado » como también es posible decir timakotake tsinane, "la mujer dio a luz a un bebé ». A partir de ese venir a existencia el principio ishire se irá desarrollando a lo largo de la vida del individuo a través de la obtención de la lengua, el aprendizaje del comportamiento social y las reglas de la sociedad. La adultez es considerada no sólo como resultado del desarrollo biológico sino también como resultado de experiencia y aprendizaje. La gente joven es designada con el término hananeki que es también utilizado para designar a cualquier individuo de cualquier especie animal en las primeras etapas de desarrollo (shiwahaniki, alevín; masherohaniki, renacuajo o sapo pequeño). La raíz antya es empleada para designar las siguientes etapas de la vida. Así, la frase yoka irihaniki antyaritake significa " el muchacho ya es adulto » y la frase yora shirampari antyashipari significa " el hombre se ha vuelto un anciano ». La gente de edad es designada con el término antyashipari (masculino) y antyashiparo (femenino) el que generalmente es traducido por « anciano » (Payne 1989, p. 368). Sin embargo este último término implica algo más que un mero proceso biológico, alude también a la experiencia y conocimiento acumulados por el individuo a lo largo de su vida. Así, de un hombre de personalidad inmadura en ashaninka se puede decir ihananeiki weitani piánaka antyashipatake, « el joven no se ha transformado en un hombre experimentado » (ihananeki, joven masculino; weitani, modal frustrativo + futuro; piánaka, transformar + perfectivo + tiempo no futuro reflexivo; antyashipatake, viejo + modal propósito + direccional al llegar + aspecto acción que ya ocurrió + tiempo no futuro reflexivo). Por el contrario, se utiliza la misma raíz para designar a los chamanes de mayor experiencia que se considera son quienes en esta sociedad han acumulado la mayor sabiduría. Así, es posible decir iroñaka ikantsi tsimatsi antyawityari, " luego había un chamán de gran experiencia » (antyawityari, raiz antya- + wi, exclamativo + tya aspecto progreso de la acción + tercera persona). La idea de transformación en el desarrollo de la persona, piánaka, es central en esta concepción. Para mostrar esto más en detalle volvamos sobre la frase ihananeiki weitani piánaka antyashipatake, " el joven no se ha transformado en un hombre experimentado ». El término piánaka, que en esta frase traducimos por « transformación » y que también puede ser traducido en otros contextos como « revivir », 
ofrece una analogía con un proceso que afecta a ciertos seres vivientes del entorno en que se desenvuelven los ashaninka, a saber el de metamorfosis en las mariposas y los escarabajos. Así, en la lengua ashaninka podemos decir tsiopa ipia santa « la larva tsiopa se transforma/revive en/como mariposa "; santayoiro itsoki ipianaka shiopa (suborden Ditrysia) «la mariposa puso sus huevos y se transformaron/revivieron en/como larvas shiopa »; itaki chirompe itsokakiro inchato ipianaka chirompe « el escarabajo chirompe (Acrocinus longimanus y Gen. Acanthoderes y Gen. Chalcolepidius) puso sus huevos en un árbol y se transformaron/revivieron en/como larvas chirompe ». Esta idea de transformación es central en la concepción ashaninka del devenir de la persona, lo que tiene que ver no sólo con el desarrollo de su ishire durante la existencia que se inicia con su engendramiento, sino con su devenir tras la muerte.

El conjunto de las representaciones ashaninka sobre los componentes de la persona, presentadas hasta aquí, son expresadas en la mitología ashaninka en el mito de Aroshi.

Mito 1 - Aroshi y el origen de las manchas de la Luna.

Antiguamente una joven fue fecundada por el ave blanca itéwani. Ella no sabía quién la había embarazado y lloraba. Pero su padre sabía que había sido embarazada por Aroshi. Aroshi le trajo piezas de caza a la joven mujer. Nació el Aroshi pequeño. Aroshi le dijo al pequeño Aroshi: "Anda y ve a la casa de la hormiga manákiri que llaman koka ». Fue a buscar a la hormiga manákiri que era su yerno (itíneri). Caminaba lloroso hasta que la encontró. Entonces empezó el (hijo de) Aroshi a hacerle sus bromas pesadas. Se burló de la flecha pequeña que tenía la hormiga (alusión al aguijón) diciéndole que con eso no mataría a nadie y lo retó a dispararle su flecha). La hormiga disparó y lo mató. Aroshi esperaba a que su hijo el pequeño Aroshi volviera a casa. Como no volvía, fue a buscarlo y lo encontró muerto. Se dijo Aroshi: « ¿De qué ha muerto? No estaba enfermo ». Así quería morir. (El tenía una piedra para revivir gente la que llevaba como collar al cuello (imairiti). (Con esa piedra) le dio el soplo de la vida y lo revivió/transformó (impoi itasonkapakeri irio iwiánaka). Aroshi regresó a su casa. Pero su hijo se fue, siguió caminando. Encontró a la esposa de un ashaninka, la sedujo y le hizo el amor. Los encontró Oteiriki (el esposo de la mujer) y trató de escapar pero este lo mató. Otra vez vino Aroshi. Lo revivió con la piedra que tenía en su collar y su madre se lo llevó. Al amanecer volvió a salir (el muchacho) y encontró una gran roca que estaba sentada. Le dijo: “ ¿Qué cosa comes que no puedes caminar? » (Se burlaba de la piedra que no podía moverse) y la retó a una carrera. La piedra entonces se dejó rodar. La piedra llegó junto a el, iban parejos y lo aplastó. El muchachito quedó debajo de un árbol. Vino Aroshi una vez más y lo sopló y lo revivió. Aroshi juntó leña y quemó a la piedra que se desvaneció. El muchacho se fue otra vez caminando y se encontró con el viento. El viento antiguamente era persona y tenía una cara alargada. El viento huracanado estaba tumbando árboles pues estaba rozando el bosque para hacer chacras. El viento gritaba para avisar que los árboles caían. Le dijo al muchacho que pasara rápido (para que no resultara aplastado) pero este no le hizo caso y le dijo que si caía un árbol lo iba a empujar. Insistió en que pasara rápido pero insistía en que empujaría el árbol. Le cayó el árbol encima y murió. La madre del muchacho lo estaba 
esperando pero no regresaba. Salió a buscarlo y lo encontró muerto. Le dio de beber, lo acarició y se lo llevó a casa. (Otra vez Aroshi) lo revivió. Nuevamente salió. Esta vez se fue al río. Se quitó la ropa y se metió al agua. Vino su madre. Como estaba desnudo, le dio vergüenza y se metió al agua. Como su madre estaba allí se sintió confiado y se sumergió. Su madre le dijo que tuviera cuidado pero el se siguió sumergiéndose y el agua del río terminó por arrastrarlo. La madre junto con Aroshi intentaron rescatar al muchacho. Se rompió el collar de Aroshi (con el que este lo resucitaba soplando). (Para resucitar a su hijo) la mujer quiso ir donde pasaba Luna Kashiri (para sacarle un pedazo y con eso resucitar al muchacho). Ella esperó a Luna por donde pasaba y lo golpeó con un bastón. Luna la vio y se puso a la mujer de collar, burlándose de ella y siguió su camino. Aroshi se burló de Kashiri que era su abuelo y quiso sacarle un pedazo pero éste intentó tragárselo. Casi lo atrapa y le rasgó la túnica dejándolo desnudo. Aroshi insistió en sacarle un pedazo y Kashiri terminó por tragárselo. Está dentro de Luna Kashiri. Quizá algún día baje. (Pablo, Río Pichis, diciembre 1989)

El personaje principal de este mito es el joven Aroshi, hijo de la divinidad llamada a su vez Aroshi que forma parte de la categoría de los tasorentsi. La historia del joven Aroshi es la de un joven hombre que rechaza sistemáticamente todo aprendizaje y toda adquisición de conocimientos, que no respeta las normas que rigen las relaciones entre los individuos en la sociedad, que no logra establecer relaciones armoniosas con los seres más poderosos que él y que constituyen un peligro potencial. Dicho de otro modo, este texto nos presenta la historia de un personaje que no llega a desarrollar su alma ishire. Es enviado por su padre a casa de su cuñado (esposo de la hermana) la hormiga, para recibir los conocimientos sobre la caza. Entre los ashaninka es una práctica usual que sea un aliado, en especial el esposo de la hermana, quien entrene a los hijos en estas técnicas (Rojas Zolezzi 1994, p. 96). Sin embargo, él se burla de su instructor quien termina por matarle. Seduce una mujer casada, siendo asesinado por el esposo. Enfrenta el poder de no humanos más poderosos que él como las grandes piedras y el viento, que le matan. Esta falta de desarrollo del ishire de Aroshi es remarcado por sus muertes sucesivas, cada vez que no llega a obtener un conocimiento o a adquirir un modelo apropiado de conducta. La sola regla que sigue quizá es aquella del pudor, de no mostrarse desnudo ante su madre, alusión a la prohibición del incesto. Pero una vez más, él subestima el poder de un ser más poderoso que él, el río, y termina ahogado. Habiendo roto la piedra del collar con la que su padre lo resucitaba soplando, el joven hombre termina por morir. En otra versión de este mito registrada por Anderson (1985, I, pp. 74-83), el pasaje de la destrucción del collar o piedra de soplo es reemplazado por el robo de éste por el colibrí tsonkiri mientras el joven se baña en el río: esto constituye una variante del mito de gran importancia. En la mitología ashaninka, los chamanes, transformados en colibríes, traen a los hombres los dones de las divinidades: las presas de caza para alimentar las familias y el tabaco para comunicarse con ellas. Según esta misma versión Aroshi decide matar a todos los colibríes para recuperar la piedra de 
soplo, lo que puede ser entendido como una acción que daña gravemente las relaciones de los humanos con las divinidades. Weiss (1975, p. 269) presenta también este pasaje, pero el resumen que ofrece del mito impide en realidad hacer uso de esta versión en el análisis. Luego del pasaje de la pérdida de la piedra de soplo, las dos versiones que seguimos aquí difieren. En la versión de Anderson, es Aroshi quien habiendo perdido su collar intenta hacerse uno nuevo con un trozo de la frente de Luna Kashiri quien lo traga; en la otra versión, son el padre y la madre del muchacho, desesperados por revivirle, quienes intentando obtener un trozo de un ser poderoso como Luna Kashiri para resucitar a su hijo terminan por ser devorados. Esta parte del mito es mejor comprendida si se toma en cuenta que Luna Kashiri pertenece a la categoría de las divinidades llamadas tasorentsi, es decir, aquellas que soplan (tasonk, soplo), los dueños del soplo de vida. Se trate del padre o el hijo, Aroshi es tragado por Luna, lo que explica la existencia de las manchas de su cara visible. El fin del muchacho Aroshi, en el gran estómago de Luna Kashiri guarda coherencia con la idea, que veremos más adelante, de que es ese el destino de las almas de aquellos que no lograron obtener un conocimiento profundo del mundo.

\section{EL CONOCIMIENTO Y EL DESARROLLO DEL ISHIRE EN LOS HUMANOS}

Los ashaninka distinguen lingüísticamente diferentes niveles de conocimiento, los cuales tienen que ver con el desarrollo del individuo y, en consecuencia, con el de su ishire. Los ashaninka distinguen entre ver, conocer y sabiduría. Ver, ñantsi o menaantsi en idioma ashaninka, es una noción que se refiere a lo empíricamente observado. Esto se diferencia del saber o conocimiento yotaantsi que se refiere al saber hacer una cosa (por ejemplo saber usar un arco con sus flechas, saber sembrar en un huerto de acuerdo a los diferentes tipos de suelo y características de los cultígenos) y al conocimiento sobre las propiedades de las cosas (reconocimiento de un tipo de planta en el bosque entre muchas otras, reconocimiento de las plantas medicinales y sus propiedades y su uso y aplicación). Éste es también el conocimiento de las relaciones entre los seres, como las relaciones de parentesco de una persona en relación a otras. Esta diferencia entre ñaantsi o menaantsi y yotaantsi me la explicó un ashaninka de la siguiente manera: « tú has llegado aquí y veo cómo eres, lo que llamamos ñaantsi. Pero yo no puedo decir que te conozco porque yo no sé quienes son tus familiares, nunca los he visto ni sé donde viven ni cómo son. Esto llamamos yotaantsi ». Adicionalmente, los ashaninka hablan de ñaawiyataantsi para hablar del conocimiento obtenido por el chamán a través de su alucinación psicotrópica por el consumo de tabaco y ayahuasca (Banisteriopsis sp.) que corresponde a lo que consideran el conocimiento más profundo del cosmos, la interioridad de los seres que lo constituyen y las relaciones entre éstos. Este conocimiento puede también ser 
logrado aunque en menor medida a través de los sueños en los cuales es posible percibir la interioridad de los seres.

Estos tres niveles de conocimiento corresponden a los de los diferentes especialistas rituales. El mahonkari es el que inició el entrenamiento para ser chamán sheripiari (literalmente, el que se transforma por el tabaco) pero no llegó a serlo porque el conocimiento chamánico no llegó a residir en él. Se trata de un especialista que cura con hierbas medicinales. A este nivel corresponden también las mujeres practicantes del chamanismo femenino awintantsiri que curan con vapor caliente y baños con hierbas las dolencias de sus parientes y vecinos. El sheripiari es el especialista ritual que cura no sólo con hierbas sino a través de las visiones que obtiene por medio de la ingestión del psicotrópico ayahuasca kamarampi (Banisteriopsis sp.): puede acceder al conocimiento de las relaciones entre los seres y descubrir así la fuente de las enfermedades de las personas, sean ellas las acciones de seres malevolentes kamari o chamanes enemigos o de brujos matsi ocultos al interior de la sociedad de los humanos atsiri. El antyawityari como ya hemos señalado es el sheripiari de gran experiencia y sabiduría que ha llegado al más alto grado del conocimiento del mundo a través de las visiones obtenidas por medio del uso del psicotrópico kamarampi. Mientras que un sheripiari tiene sólo influencia local, estos últimos curan a personas de toda una región y en ocasiones emprenden giras entre las comunidades. El chamán sheripiari antyawityari es considerado como el que ha alcanzado el grado más alto de desarrollo de su ishire por su mayor conocimiento del orden cósmico. De la adquisición de estos conocimientos dependen las posteriores transformaciones del individuo humano tras la muerte. Los chamanes son los únicos humanos con la capacidad de transformar su fisicalidad a voluntad sin transformar su interioridad. Pueden tomar la forma de un colibrí como hemos visto en el análisis del mito citado para traer los dones de las divinidades, pero pueden tomar asimismo la forma de un jaguar maniti con el fin de devorar a quienes dentro del grupo residencial en que habitan se alejan de las reglas de la sociedad o para atacar individuos de otros grupos residenciales enemigos.

Existe en este sistema sin embargo una categoría de seres que son el resultado de un desarrollo aberrante de su interioridad y que en cierta manera son el inverso de los chamanes: se trata de los llamados matsi. El individuo humano en las primeras etapas de su vida puede ser captado y entrenado por estos seres malevolentes kamari adquiriendo la capacidad de devorar a distancia los órganos internos de sus parientes y otros miembros de la comunidad a través de la manipulación ritual de restos de la comida de sus víctimas, suerte de apetito desmesurado y mal dirigido hacia una suerte de canibalismo. Debido a ello, los bebés en sus primeros años de vida son especialmente vigilados y mantenidos a distancia del suelo suspendidos en pequeñas hamacas de fibras de corteza a fin de que ningún kamari se les acerque en forma de insecto, en especial los grillos. Si un chamán sheripiari es quien más ha desarrollado su interioridad a través del 
conocimiento obtenido en la relación con las divinidades maninkari, la interioridad de los matsi es construida a partir de modelos de relación y conocimientos asociales obtenidos por medio de la relación con los seres malevolentes kamari. Si el chamán puede cambiar de forma manteniendo su interioridad como persona sin cambios, el matsi mantiene la forma humana a pesar de haber sufrido una transformación de su interioridad. Estos individuos, aun cuando mantienen la forma humana, no son verdaderos atsiri sino kamari y sólo pueden ser detectados por el chamán en sus visiones.

\section{ESTABILIDAD DEL CUERPo y RELACIONES ADECUAdAS CON LOS NO HUMANOS}

La calidad de humano puede ser perdida por el individuo que se aleje demasiado del entorno de las relaciones entre humanos. En este sentido, el ámbito de las relaciones con los animales, el bosque, es siempre peligroso, pues de perderse en él, el cazador corre el riesgo de transformarse en un no humano. A este respecto, la lengua ashaninka presenta el término inchatoshinari, que designa tanto a los animales que habitan en el bosque como a los individuos originalmente humanos que perdieron sus características sociales al perderse en la floresta y se quedaron a vivir en ella. Se trata de individuos que perdieron completamente sus relaciones con los humanos. Un ejemplo de estos peligros es expresado en el siguiente mito referido a las aventuras de un cazador:

Mito 2 - Un hombre se fue a cazar y mató un venado. Sin embargo vino un oso que se llevó la presa y la subió a un árbol. La persona (atsiri) se quedó con hambre. Lloró. Sacó las orugas del corazón de una palmera para comerlas. Luego vino el oso para llevárselo a él. El monstruo korinto le había dicho al oso que le trajera al cazador para devorarlo. El hombre se puso las orugas en las orejas, los ojos, el ano y se echó sobre el suelo aparentando estar muerto. El oso introdujo una garra en el ano del hombre. Trajo hormigas e hizo que le picaran, pero a pesar del dolor que le causó todo esto, el cazador no se movió. El oso se lo llevó. Pero como apestaba y tenía gusanos, tomándolo por una carcasa podrida, el oso lo dejó. El hombre se levantó y huyó. Luego encontró el venado que había cazado todo podrido. Encontró luego su escopeta y hasta su túnica que le había quitado el oso que le había desvestido. Pero la túnica había sido destruida por el comején (kairo). El hombre tuvo que vestirse sólo con trusa. Demoró mucho (osamani) en volver a su casa. Tuvo buena suerte y logró matar un paujil kentsori (Tinamous tao) en el camino. Su madre al ver que no volvía lo había llorado. El explicó que el oso se lo había llevado y narró la manera como evitó que le matara aparentando estar muerto y cubriéndose de orugas. Le dieron de comer yuca y comió mucha. Pero ya había empezado a crecerle pelo. Le creció mucho pelo como al oso y se volvió todo peludo (iwitseyetake) como el oso, flexible (iyentatake) de menor tamaño e inmaduro (irohanikitaque) y empezó a trepar a las ramas de los árboles. « El ya no tenía el aspecto de personas verdaderas como nosotros por estar viviendo allá en el bosque frío » (irirori te asheyanahiari akemitaka anoni atsirira kariperotaque okantanaheri antámira 
tsikawentseriri katsikaiteri seikawaitapahi). Más tarde, una mujer le dio una túnica nueva y se casó con ella. (Wancho, Río Perené, 1986)

En esta narración, encontramos una explicación de los peligros a los que el cazador ashaninka se ve expuesto cada vez que ingresa al bosque antamimashi, ámbito de alejamiento extremo de los humanos. En principio, para conjurar los peligros de tal alejamiento y el ataque de los seres poderosos del bosque, los cazadores ashaninka van siempre acompañados de un afín (Rojas Zolezzi 1994, p. 96). El personaje de este texto oral por el contrario se interna solo en este ámbito. El oso maini (Tremarctos ornatus) es considerado dentro de la mitología ashaninka nieto de korinto, uno de los monstruos caníbales míticos a los que los chamanes encerraron en grandes cavernas al inicio de los tiempos, pero los que se cree se presentan aún en reducido número en puntos remotos del bosque. Este es descrito como un cuadrúpedo de gran volumen provisto de una gran trompa prensil con la que atrapa a sus víctimas y se las lleva a la gran boca que tiene en el lomo. El oso es asociado a este ser malevolente por ser el animal más grande del bosque. El cazador de la narración es pues presentado como enfrentado a algunos de los mayores peligros potenciales presentes en el ámbito del bosque. Tras el encuentro con el oso, habiendo perdido el camino de regreso, el cazador pasa una larga temporada en el bosque, al punto que su cuerpo sufre cambios. Para explicar este proceso, la narradora hace uso del término ihananeki, el que anteriormente hemos visto aplicado a las personas para expresar la idea de inmadurez, falta de sabiduría y experiencia. En este caso, sin embargo, no se trata de la inmadurez de un joven falto de experiencia sino de una pérdida radical de los aspectos humanos del individuo. Al punto que se opera una transformación de su apariencia física y forma de locomoción. La narradora nos habla aquí de una pérdida de la forma correspondiente a los humanos en el cazador. Este aspecto es subrayado por los pasajes en que se señala el reemplazo de su túnica, cubierta externa propia a los humanos, por el pelaje que aparece en su piel y el cambio del desplazamiento sobre el suelo por el de las copas de los árboles, lo que corresponde a los animales clasificados como mitahachiri. A pesar de que al retornar a su casa es alimentado con yuca, el alimento cultivado propio a los hombres, ha perdido algo de su humanidad. Logra recuperarla sin embargo cuando una mujer le ofrece una nueva túnica (itsare). Este don va acompañado de un ofrecimiento de alianza matrimonial lo que permite al individuo rehacer sus relaciones en el ámbito de los humanos, las que había perdido durante su largo aislamiento en el bosque.

El individuo que cae en la condición de inchatoshinari revela una falta de conocimiento acerca del mundo del bosque y el cosmos. En este sentido, constituye una forma errónea de relación con los seres del bosque, dominio organizado por los dueños de los animales, los iriri, seres que constituyen parte de los maninkari o divinidades ancestrales que habitan en las alturas, ya sea en las cimas de los cerros, sobre las nubes, o como parte de las estrellas de la vía láctea. Es a 
través de la figura del dueño de los animales, como hemos visto, que en este sistema es definido el modelo de las relaciones adecuadas con las presas que habitan en el bosque, ámbito de la cacería. Categoría de divinidades donadoras de presas a los cazadores ashaninka, los dueños de los animales exigen el cumplimiento de un estricto código de reglas de purificación del cuerpo y el consumo de la carne que permite que las presas se acerquen al cazador. Asimismo exigen el manejo eficaz de las armas de manera que se evite el perder las presas heridas de muerte al huir en el bosque, desperdicio del recurso que puede afectar el envío de nuevas presas (Rojas Zolezzi 1994, pp. 179-194). El seguimiento de estas reglas puede llevar a un cazador experto a establecer una relación privilegiada con el dueño de los animales al llegar a seducir a la hija de éste y convertirse en su yerno. A un cazador exitoso se le puede atribuir el mantener una relación conyugal en secreto con la hija del dueño de los animales, relación paralela a la que sostiene con una mujer en el grupo residencial en que habita y en el que distribuye las presas obtenidas en sus actividades cinegéticas.

Sin embargo la relación con el dueño de los animales es una relación llena de tensiones en la medida en que, en lugar de ser el yerno quien ofrece las presas a la familia de la esposa, como es la regla entre los ashaninka, es el dueño de los animales, en la posición de suegro, quien se las ofrece al yerno. Asimismo, el hijo del cazador con su esposa humana corre peligro de ser atacado por el dueño de los animales en el primer mes de vida, al encontrarse éste en una relación análoga a la que este ser sostiene con las presas. En efecto, interdicciones alimenticias y de actividades a fin de impedir la malformación del individuo en gestación, su pérdida o que nazca idiota, es decir, que no pueda desarrollar su alma ishire, comprometen tanto a la madre como al padre. Este último está prohibido de ir a cazar, y tanto el como su esposa se encuentran prohibidos de comer la carne de los animales del bosque pudiendo solamente alimentarse de pescado y yuca cocida. Estas prohibiciones guardan relación con el hecho de que el cazador se ha vuelto ashitarori entsira « dueño del niño » lo que lo ubica en una relación análoga a la que los dueños (ashitarori) de los animales sostienen respecto a las presas. Al encontrarse en una relación análoga, de la misma manera que el cazador mata a los hijos de los dueños de los animales, estos mismos seres míticos pueden a su vez agredir al niño que deviene presa de éstos. Debido a ello, la interdicción de cazar se extiende incluso un mes después del nacimiento del niño a fin de evitar que éste caiga enfermo y muera por acción de los dueños de los animales.

Es respecto a este problema que la categoría de los animales llamados piratsi, wirachi o wiratsi, la cual se opone a la de inchatoshinari juega un rol de la mayor importancia. El término piratsi puede ser traducido como « los animales que son criados ». Hace referencia, en primer lugar, a los animales familiares, largamente reportados a todo lo largo de la cuenca amazónica, es decir aquellos animales atrapados en el bosque vivos y que son llevados al ámbito doméstico de la casa para ser criados (Erikson 1984). Se trata, en el caso de los ashaninka, de los pollos 
de guacamayos y loros atrapados en sus nidos, las panguanas o perdices jóvenes pachiri (gen. Cryptorellus sp.), las palomas (gen. Columbidae), los perros salvajes jóvenes y domesticados komero (Atelocyntus microtis) y los jóvenes tapires kemari (Tapirus terrestris) atrapados cuando el cazador ha matado a la madre. Por extensión, luego del contacto europeo, fueron incorporadas a esta categoría las aves de corral, los perros domésticos, las ovejas y las vacas. En lengua ashaninka, un individuo se referirá al guacamayo, la paloma o la perdiz que cría como piratsi y para señalar su posesión sobre dicho animal irinti nowira, literamente, " este es aquel que yo crío » (nowira, no- primera persona singular + piratsi ${ }^{4}$ ). Sin embargo, en esta concepción, se dice que los maninkari crían a los animales del bosque y, de hecho, el término piratsi o wiratsi es utilizado para designar a una variedad de pecari o huangana, el tayassu peccari. Siendo el género tayassu en general reputado como peligroso y agresivo, la especie tayassu peccari según los ashaninka contrasta con la especie tayassu tajaccu no sólo por ciertas diferencias morfológicas sino porque en ésta se aprecia de manera más acusada un cierto gregarismo. De hecho, aunque igualmente agresiva, esta especie se desplaza en bandas por el bosque. Estos grupos son considerados análogos a los hatos de ovejas o auquénidos que los ashaninka han observado en sus vecinos los quechuas de las tierras altas. Asimismo, los comparan a las aves de corral de su casa. De hecho, a los tayassu peccari se les atribuye estar al cuidado de un manínkari femenino, la dueña de los pecaríes, la cual mantiene en esta concepción una relación análoga a la que sostiene una mujer ashaninka con las gallinas de su casa. Así, el caso de los tayassu peccari, partiendo del gregarismo de este animal, es considerado el prototipo de la relación que, en último término, todas las especies animales que son presas de los cazadores sostienen con un manínkari, el que se considera las cuida, aunque en la mayoría de los casos se trate de seres masculinos. Con el traslado de un animal del bosque al ámbito doméstico de la casa, hombres y mujeres establecen una relación análoga a la de los dueños de los animales respecto a las potenciales presas que habitan en el bosque. De este modo, la categoría de piratsi involucra paradójicamente tanto a aquellos criados por la persona en el ámbito doméstico de la casa como a los silvestres incluyendo a uno de los animales más feroces del bosque, en la medida en que se les atribuye ser criados por el dueño mítico o la dueña mítica en lo alto de los riscos donde habitan. Si la caza es siempre fuente de perturbación de la relación entre el cazador y el dueño de los animales, los animales familiares, aun cuando se trate de una cantidad ínfima de individuos en relación a la de aquellos cazados, constituyen, en la medida en que son alimentados y cuidados de los predadores por el cazador, un mecanismo paliativo de estas tensiones. Dicho mecanismo se encuentra bastante extendido en la Amazonía, como ha mostrado Erikson (1984), para resolver las tensiones entre el cazador y el dueño de los animales. Sin embargo, entre los ashaninka, quienes avecinan a pueblos quechuas de los Andes con una antigua y fuerte tradición de domesticación, existiría la posibilidad que, por 
influencia de los pueblos de pastores vecinos, animales aprisionados fueron utilizados como alimento, hecho excepcional entre los pueblos amazónicos en que éstos cumplen la función simbólica señalada (Denevan 1974, p. 105; Weiss 1975, pp. 538-539; Rojas Zolezzi 1994, p. 142).

Estas concepciones acerca de las relaciones consideradas adecuadas con los animales que constituyen presas, son remarcadas por diferentes mitos que nos hablan de las consecuencias de relaciones inadecuadas con éstos, de los cuales presentamos aquí un ejemplo:

Mito 3 - Un cazador se encontró en el bosque con un tapir hembra con la que sostuvo relaciones sexuales. No podía sacar su pene. Cuando finalmente logró sacarlo, notó que el pene hablaba. El hombre regresó a su casa. Al llegar saludó a su esposa diciendo: "He llegado ». A su vez el pene lo imitó diciendo: « He llegado ». El pene repetía todo lo que decía. Desesperado, intentó envenenar su pene con un piscícida (Lonchocarpus $s p$.). Finalmente se ahorcó con una soga. Entonces se transformó en la pequeña ave pitsinte (no identificada). (Jorge, C. N. Cutivireni, Río Ene, 1999)

El contacto sexual del cazador con el tapir hembra en lugar de la relación adecuada con su esposa humana lleva a una transformación del cuerpo del primero en las forma y funciones de sus órganos, lo que lo lleva a una situación de ridículo. Modos de relación inadecuados con no humanos y la interrupción de estas relaciones en el ámbito de los humanos llevan pues cambios en la forma del cuerpo del individuo, es decir en su fisicalidad, y a la pérdida de la condición de humano. En el caso de las muchachas, sus capacidades reproductivas son restringidas en el plano simbólico únicamente a la producción de humanos ashaninka. Los ashaninka consideran que una joven púber puede ser fecundada no sólo por un hombre, sino por otros seres poderosos del bosque o del río. Como ha señalado Weiss (1975, p. 435), fetos abortados en las primeras etapas de desarrollo son considerados como el producto de la acción de seres malevolentes kamari. Sin embargo el peligro más importante para las jóvenes es Kiatsi, el padre de los peces quien se cree puede fecundarlas cuando van al río. Durante una reclusión que durará todo un mes lunar a partir de la primera menstruación, a través de pinturas corporales que impedirán que Kiatsi la fecunde, la capacidad de reproducción de la mujer es definida. Como hemos señalado en otra parte (Rojas Zolezzi 1994, pp. 119-120, 123), estos diseños corporales representan la piel de Kiatsi, que se presenta en la forma de una gran serpiente acuática, quien confundirá a la joven con un ser similar a el y no la fecundará.

\section{FORMA, RELACIONES ENTRE LOS SERES Y JERARQUía}

La muerte es considerada un proceso de transformación (pianaka) por el que los individuos humanos se transforman en diferentes seres de acuerdo al grado de desarrollo de la interioridad alcanzado, lo que guarda relación con el carácter de 
las relaciones que uno establece con los otros seres, humanos y no humanos a lo largo de su vida y los conocimientos que ello implica. Dichos seres se sitúan en diferentes puntos del cosmos que es concebido como estratificado. Así, el chamán sheripiari, quien ha logrado el nivel más alto de desarrollo de su ishire, tiene por destino el área llamada inkite a la altura de las nubes en la bóveda celeste, entre la tierra kipatsi y el henoki situado más alto, donde habitan los tasorentsi (el sol, la luna y otros planetas). El ámbito del inkite es donde habitan los maninkari. Éstos son seres antropomorfos que visten túnicas de color amarillo resplandecientes lo que los ubica a medio camino entre los humanos que habitan en la tierra y Oriatsiri, el sol, el humano brillante, el más perfecto. Se dice, asimismo, que un relámpago es un alma ishire que cae luego de intentar entrar en las comunidades del cielo y no ser admitida. El siguiente texto de la tradición oral ashaninka presenta algunos aspectos de estas representaciones.

Mito 4-La golondrina etsoni (Cypseloides rutilus y Atticora fasciata) (que era un hombre) subió hasta el cielo henoki. Abrió la entrada al cielo y vio a aquellos que se encontraban allí que estaban en una reunión de bebida. Los que estaban al interior vieron llegar a etsoni y lo escucharon silvar con la ayuda de sus manos, alusión a su canto. Ellos dijeron: « ¿Quién es ese que se está lamentando? ». Enviaron a uno de ellos a ver de quién se trataba. El vio (a etsoni) que había llegado. Preguntó a etsoni: « ¿A dónde vas? ». El respondió: « He venido tan sólo a visitarles ». Ellos le dijeron: « Está bien que vengas, tu puedes quedarte aquí ». [Pero etsoni] quería entrar más lejos, allá a donde ellos (los tasorentsi) habitan. Pero ellos le dijeron que no debía entrar al interior y quedarse en ese lugar. El se quedó allí. Luego le dijeron: "Vamos a alegrarnos ». Le dieron a etsoni una flauta de pan sonkari y éste comenzó a danzar mientras la tocaba. Pero (uno de los que se encontraba allí bebiendo) dijo: « Éste no es chamán sheripiari. Que sufra y que soporte ". Luego se vio caer a etsoni hacia abajo (osawiki). Se dice que se transformó en el ave mapityontyo (no identificada). Cuando vieron que caía desde lo alto, sonó el trueno. El cayó porque no era un verdadero chamán sheripiari. Él no podía ir más alto y debía quedarse a vivir en el bosque (otishiki) transformado en un pequeño pájaro mapityontyoki. No le permitieron tomar el camino que le llevaba más alto, el camino por el cual él quería ir. Si él no hubiera silvado con sus manos, ellos no lo hubieran visto y no hubiera entrado donde aquellos ashaninka bebían cerveza de yuca. Pero ellos le escucharon y le preguntaron a dónde iba. Si no hubiera hecho eso y hubiera conocido el camino, habría podido pasar. Él dijo que sólo había venido de visita y que no quería ir más lejos. Le hicieron tocar la flauta de pan y disimuladamente lo llevaron al lugar por donde salen los rayos para hacerlo caer hacia abajo, cayendo en el bosque. Ahora él habita allá, en el bosque, tranquilo (transformado en ave mapityontyoki). Esto que yo digo, es lo que yo escuché antiguamente. He terminado. (Jorge, C.N. Cutivireni, Río Ene, 1999)

Etsoni, que en el tiempo primordial era un humano, según este mito no poseía el nivel de conocimientos suficiente para habitar el cielo henoki cerca de los tasorentsi, razón por la cual es lanzado de nuevo a tierra por los sheripiari que habitan allí tras la muerte y que se han convertido en manínkari. Al entrar en la 
categoría de manínkari los muertos pierden su identidad en tanto que individuos para sumarse a un conjunto indiferenciado de ancestros de manera que podemos hablar de una ancestralidad generalizada, pues todos los ashaninka los consideran globalmente sus ancestros. Por debajo de los chamanes, hay ashaninka que acceden a la comunidad de los muertos ubicada en un nivel del cosmos bajo esta tierra y viven en ella felices transformados en seres luminosos. En el camino a la tierra de los muertos, en el viaje por el río, deberán sin embargo evitar caer en la gran trampa de pesca construida por Luna Kashiri en el tiempo primordial; pues serán entonces devorados por éste y retenidos en su estómago, lo que dependerá del grado de conocimiento de la cosmología en general de los individuos. Niños y mujeres, dado su bajo nivel de conocimiento del ordenamiento y fuerzas en juego en el cosmos, se cree que a la muerte caerán en esta trampa. Asimismo, quienes mueren de enfermedad se considera que han sido víctimas de algún ser cuyo poder no han podido evitar o con el que han tropezado, lo que es considerado el resultado de un limitado conocimiento de las fuerzas del cosmos y se les atribuye por consiguiente terminar en el vientre de la luna, luego de caer en la trampa señalada. La gente común que no ha logrado un alto nivel de conocimientos y siempre sospechosa de haberse unido en un grado ilícitamente cercano de parentesco de manera furtiva o de no haber sido suficientemente recíproca con los demás se cree pueden transformarse en otros animales de caza. Éstos son los que los ashaninka llaman peyari, literalmente «transformados », término derivado de piánaka, " transformar ». Se considera que éstos han sido rechazados al querer entrar al cielo henoki y caen a tierra en forma de rayos para convertirse en diferentes animales, como en el caso de etsoni en el último mito citado. Son consideradas peyari las presas que aparecen cerca del asentamiento por la época en que ha muerto en éste una persona y se cree que dicho animal es el humano fallecido transformado en un mamífero al no haber tenido el nivel de conocimiento para entrar en el cielo henoki. Debido a ello, los animales cazados cerca del asentamiento en fechas próximas a un deceso no se les come como precaución, pues se cree que se trata de la transformación del difunto. Esta concepción se expresa lingüísticamente en que a los animales sospechosos de ser peyari les llaman por su nombre seguido por el sufijo -niro. Desde luego, el animal que sería un peyari en un asentamiento en que ha ocurrido una muerte reciente, no lo es para otros asentamientos, que ignorantes de todo esto, eventualmente lo atraparán y comerán. El hecho de que un animal es reconocido como un peyari depende de la adscripción del observador a un asentamiento con un muerto reciente. Lo que es un peyari para los miembros de un asentamiento se convierte en poshini, " alimento », para los demás asentamientos. En algunos casos los espíritus ishire de algunos de estos muertos pueden insistir vanamente en seguir en comunicación con sus parientes y rondan el asentamiento donde vivían volviéndose fantasmas shiretsi (término derivado del anterior) los cuales ocasionan a los vivos con este torpe comportamiento una serie de enfermedades. En 
otros casos, sus ishire pueden permanecer en sus cuerpos y tras algún tiempo vagando por el bosque se transforman en un tipo de mamífero terrestre. Éstos son también considerados peyari (González, in Izaguirre 1929, XII, p. 275). Según Lenaerts (2002, p. 220), el ciervo maniro (Mazama sp.) y el kinkajú kitha o kitsani (Potos flavus) son considerados formas que a menudo toman estos difuntos. Sin embargo, otros informantes subrayan la idea de que quienes no han sido respetuosos de la norma de distribución y que han quebrado la más importante regla de distribución y reciprocidad, a saber la regla de incesto, se transforman tras la muerte en los pecaríes denominados piratsi (Tayassu peccari) a los que ya hemos aludido. Según Elick, si se trata de un chamán que ha cometido el incesto, éste se transforma en un agutí sharo (Dasyprocta variegata) (Elick 1969, p. 225). En todos estos casos se trata de individuos que quedan bajo el cuidado de los dueños míticos de las especies respectivas en calidad de potenciales presas de los cazadores. Si como hemos señalado, a pesar de la fisicalidad distinta evidente, se atribuye a los animales una interioridad y forma de vida y modos de conducta similares a los de los humanos, dicha interioridad es en comparación a la de los humanos incompleta: si los humanos sostienen relaciones de consanguinidad y afinidad, los animales presentan relaciones de afinidad imperfectas ya que pueden cometer uniones dentro del ámbito de la consanguinidad y de allí que quienes cometan incesto se transformen tras la muerte en animales. Los guerreros tendrían más de un destino. De una parte, se dice que existe una tierra de los guerreros asesinados itentari donde ellos habitan como seres malevolentes kamari. De otra, como señalan los informantes de Weiss, los mejores entre ellos pueden entrar al servicio de amempori (Vultur gryphus), creencia compartida por los vecinos arawak amuesha (Santos Granero 1991, ppp. 37-39) y matsiguenga (Baer 1995, p. 86) transformándose en estas aves. Dada que la relación social por excelencia es la del intercambio, los guerreros en tanto que asesinos practican la negación del intercambio y se transforman así en aves de presa. Sin embargo, en tanto que todos estos no humanos son poseedores de una interioridad similar a la humana, son ubicados dentro de la red de relaciones sociales de éstos: si aquellos que entran en el cielo henoki devienen ancestros y por lo tanto son ubicados del lado de la consanguinidad, los que se transforman en presas son ubicados del lado de la afinidad.

\section{Conclusiones}

Las informaciones hasta aquí detalladas nos autorizan a decir que el sistema de representaciones ashaninka presenta una ontología de tipo animista, entendiendo por este término que los humanos atribuyen a los no humanos una interioridad similar a la suya (Descola 2005, p. 238). Las especies animales y las especie de plantas cultivadas son consideradas personas, cuya forma o exteriori- 
dad fue transformada en el tiempo primordial por el demiurgo u otras divinidades dentro del proceso que lleva de un estado inicial de indiferenciación de los seres al de la definición de jerarquías entre los seres que da lugar al ordenamiento actual del cosmos y al modelo actual de relaciones adecuadas con dichos seres. $\mathrm{Si}$ existe una heterogeneidad evidente en la fisicalidad, de forma y comportamiento entre humanos y no humanos, tanto a unos como a otros se les atribuye una interioridad similar reconociéndoles a todos la calidad de personas. Asimismo humanos y animales comparten una misma cultura. Sin embargo, la interioridad de los seres es entendida como constituida por más de un componente, y se atribuye al desarrollo de uno de éstos, el ishire, en la forma de despliegue de relaciones adecuadas con humanos y no humanos según los modelos socialmente establecidos que ello implica, la posición jerárquica de los humanos sobre los no humanos, y de las divinidades ancestrales sobre los primeros. En cuanto a los no humanos, según este sistema de representaciones, a pesar de la fisicalidad evidentemente distinta a la humana, se les atribuye el interactuar entre sí y comunicarse con sentimientos, intenciones y medios semejantes a los de los humanos lo que nos lleva a pensar que se les atribuye también percibirse entre sí como humanos.

Esta ontología es parte de una cosmología de carácter relacional, ya que las identidades individuales así como su adscripción a las diferentes categorías de seres dentro de este cosmos jerarquizado (atsiri, maninkari, kamari, poshini, ikaharantayete, wiratsi, inchatoshinari, peyari), se definen por el carácter de las relaciones que sostienen con los otros seres que forman parte del sistema. Modelos de relaciones adecuadas entre estos seres son establecidos en el tiempo primordial, y el alejamiento de éstos puede llevar a la pérdida de la calidad de humano. La calidad de humano es pues una posición que el sujeto, siempre en movimiento, puede obtener o perder: a través del umbral de la muerte, los humanos que se alejan de las reglas de la sociedad dejan de ser humanos para transformarse en presas dentro de una concepción jerarquizada de los seres vivientes.

Estas representaciones generan de otra parte una serie de tensiones respecto a la relación con los no humanos que son aprehendidas a través de la figura del manínkari dueño de los animales y en parte aliviadas a través de la figura del animal silvestre criado en el hogar humano. Las representaciones sobre las relaciones con los animales definen el ámbito de la reproducción sexual de los humanos excluyendo de ésta a los no humanos. Compartir estos modos de la acción es compartir un mismo punto de vista respecto a los otros seres vivientes y de esta manera formar parte de un colectivo, los humanos por excelencia, los ashaninka. De este modo la sociedad ashaninka realiza todo un trabajo, que tiene por finalidad estabilizar al sujeto humano en su forma y aptitudes.

Finalmente debemos señalar que forma parte de esta cosmología relacional la concepción de un tiempo cíclico, de cataclismos cósmicos y destrucción de poblaciones humanas sucesivas. El alejamiento de las reglas de la sociedad y la 
pérdida de los conocimientos que a ellas corresponden puede llevar a la proliferación de la guerra en detrimento de las relaciones de intercambio propias a los humanos; asimismo hace a los individuos vulnerables a la pérdida de la forma humana, a los ataques de los seres malevolentes kamari y a su transformación tras la muerte en otros nuevos seres malevolentes. Este deterioro del entorno social lleva finalmente a un cataclismo cósmico, mecanismo de purificación, tras el cual surgirá una nueva humanidad ashaninka.

\section{NotAs}

1. Los ashaninka constituyen un grupo de horticultores de roza, cazadores, pescadores y recolectores de la familia arawak en su rama maipureana y se encuentran en la región de las cabeceras del río Ucayali, que comprende los ríos Perené, Ene, Tambo, Pichis, Pachitea, Urubamba y la región interfluvial del Gran Pajonal en Perú en el pie de monte oriental de los Andes centrales. Durante la época del caucho una parte de esta población fue llevada a las zonas de los ríos Juruá y Envira en el territorio de Brasil.

2. Tonki, para designar los huesos de hombres, animales y los tallos leñosos de los vegetales y el raquis de las hojas de las palmeras; owatsa para referirse a la carne del cuerpo humano y de los animales, la pulpa del tronco de un árbol, de las raíces suculentas y de los frutos; kashi designa tanto el esperma masculino humano y animal como la savia blanca de ciertos árboles.

3. En la cuenca amazónica, es posible encontrar concepciones similares entre los jívaros (Taylor 1996, 1998) y los vecinos de los ashaninka, los arawak piro yine (Gow 1991).

4. En el lenguaje ashaninka, existe una regla morfofonológica de debilitamiento de la oclusiva $p$ en posición inicial en un lexema nominal, relajándose su modo de articulación cuando se encuentra en contacto con un prefijo posesivo. Otros ejemplos de esto son el lexema nominal pankotsi « casa » que se transforma en nowane " mi casa » o él señalado por Patte (1993, p. 115; Payne 1989, p. 69) pachaka (calabaza, Lagenaria sp.) que se transforma en owachakate « su calabaza ».

\section{BIBLIOGRAFÍA}

AlÈs Catherine

1998 «Pourquoi les Yanomami ont-ils des filles? », in Maurice Godelier y Michel Panoff (eds), La production du corps : approches anthropologiques et historiques, Éditions des archives contemporaines, Amsterdam, pp. 281-316.

ANDERSON Jaime R.

1985 Cuentos folklóricos de los asháninka, 3 vol., CALAP-ILV, Yarinacocha.

BAER Gerhard

1995 Cosmología machiguenga, Abya-Yala-CAAAP, Quito.

BERLIN Brent

1992 Ethnobiological classification: principles of categorization of plants and animals in traditional societies, Princeton University Press, Princeton N. J. 
BUTNER Thomas

1989 La rojez de anoche desde la cabaña, Editorial Colmillo Blanco, Lima.

Crocker J. Christopher

1983 "Les réflexions du soi », in Claude Lévi-Strauss (ed.), L'identité : séminaire interdisciplinaire, PUF, Paris [1977].

Da Matta Roberto, Anthony Seeger y Eduardo Viveiros de Castro

1979 "A construçao da pessoa nas sociedades indigenas brasileiras », Boletim do Museo Nacional, 32, pp. 2-19, Rio de Janeiro.

DenEvan William

1974 "Campa subsistence in the Gran Pajonal, Eastern Peru », in Patrice Lyon (ed.), Native South America. Ethnology of the least known continent, Little, Brown and Company, Boston, pp. 92-110.

Descola Philippe

$2005 \quad$ Par-delà nature et culture, Gallimard, Paris.

ELICK John

1969 An ethnography of the Pichis Valley Campas of Eastern Peru, Ph. D., University of California, Los Angeles.

ERIKson Philippe

1984 «De l'apprivoisement à l'approvisionnement : chasse, alliance et familiarisation en Amazonie amérindienne », Techniques et cultures, 9, pp. 105140 .

Fernández Eduardo

1984 "El águila que comía gente y el origen de los piro. Mitología ashaninka », Amazonía Peruana, 10, pp. 129-142, Lima.

1986 Para que nuestra historia no se pierda, CIPA, Lima.

GonzÁlez Bernardino Fr.

1929 «Ojeada sobre la montaña. Exploración al Cerro de la Sal. Algunas costumbres de los indios » [1891], in Bernardino Izaguirre Fr., 1921-1929, Historia de las misiones franciscanas y narración de los progresos de la geografia en el oriente del Perú, vol. 10, p. 400, Talleres tipográficos de la penitenciaría, Lima.

Gow Peter

1991 Of mixed blood. Kinship and history in the Peruvian Amazon, Clarendon Press, Oxford.

HuGH-JoNES Christine

1979 From the Milk River. Spatial and temporal processes in northwest Amazonia, Cambridge University Press, Cambridge.

KINDBERg Willard

1956-1960 Textos campa ashaninka III, Información de campo n 47, Rollo 5, microfilm, Instituto Lingüístico de Verano, Yarinacocha. 
LENAERTS Marc

2002 Nos saurs manioc et l'étranger jaguar : diversité et changement des savoirs sur les êtres de la nature, chez les Ashéninka " de l'Ucayali» (Amazonie péruvienne et brésilienne), thèse de doctorat en anthropologie, université libre de Bruxelles, Bruxelles.

PATte Marie-France

1993 "La fiancée de l'arc-en-ciel, mythe ashéninka », Amerindia, 18, pp. 109139.

PAYNe Judith

1989

Lecciones para el aprendizaje del idioma ashaninka, Ministerio de educación-ILV, Lima.

\section{Rojas Zolezzi Enrique}

$1994 \quad$ Los ashaninka, un pueblo tras el bosque. Contribución a la etnología de los campa de la selva central peruana, Fondo editorial de la Pontificia Universidad Católica del Perú, Lima.

1997 "Origen y clasificación de las plantas cultivadas en el pensamiento mítico ashaninka ", Antropológica, 15, pp. 255-288, Lima.

2003 "Las clasificaciones ashaninka de la fauna del piedemonte central: un caso de diferentes niveles de aproximación ", Bulletin de l'Institut français d'études andines, 32 (1), pp. 185-212.

$2004 \quad$ Mythes de la création du monde, représentations du gibier et des plantes cultivées, et définition de l'ordre social traditionnel chez les Campa Ashaninka de l'Orient péruvien, thèse de doctorat en anthropologie sociale et ethnologie, EHESS, Paris.

\section{Santos Granero Fernando}

1991 The power of love. The moral use of knowledge amongst the Amuesha of Central Peru, The Athlone Press, London.

\section{TAYLOR Anne-Christine}

1996 "The soul's body and its states: an Amazonian perspective on the nature of being human ", Journal of the Royal Anthropological Institute, 2, pp. 201-215.

1998 "Corps immortels, devoir d'oubli : formes humaines et trajectoires de vie chez les Achuar ", in Maurice Godelier y Michel Panoff (eds), La production du corps : approches anthropologiques et historiques, Éditions des archives contemporaines, Amsterdam, pp. 317-338.

\section{VARESE Stefano}

1970 "Dos versiones cosmológicas campa », Revista del Museo Nacional, XXXVI, pp. 164-177, Lima.

VIERTLER Renate

1979 "A noçao de pessoa entre os bororo ", Boletim do Museu Nacional, 32, pp. 20-29, Rio de Janeiro. 
VILAÇA Aparecida

2002 "Making kin out of others in Amazonia », Journal of the Royal Anthropological Institute, 8, pp. 347-365.

Viveiros de Castro Eduardo

1979 "La fabricaçao do corpo na sociedade xinguana ", Boletim do Museu Nacional, 32, pp. 40-49, Rio de Janeiro.

1998 "Cosmological deixis and Amerindian perspectivism », Journal of the Royal Anthropological Institute, 4 (3), pp. 469-488.

Weiss Gerald

1975

Campa cosmology. The world of a forest tribe in South America, American Museum of Natural History, Anthropological papers 52, New York. 